\title{
ACUTE NITROBENZENE POISONING: CASE FATALITY AND IMPORTANCE OF METHYLENE BLUE
}

\author{
Abhishek Srivastava ${ }^{1}$, Amrita Chaturvedi ${ }^{2}$,Surender Kumar Gupta ${ }^{3}$, G. R. Agarwal $^{4}$, R.K.Verma ${ }^{5}$ \\ ${ }^{1,2,3}$.M.B.B.S., Junior Residents \& M.D. Student ${ }^{4}$ M.D., Reader \\ Department of Anaesthesiology, Institute of Medical Sciences \\ Banaras Hindu University, Varanasi, 221005, INDIA \\ *Corresponding author : sriva4u@gmail.com
}

Key words : methylene blue, nitrobenzene

\begin{abstract}
Nitrobenzene poisoning is a rare but fatal condition. It causes methaemoglobinemia $\left(\mathrm{Fe}^{3+}\right)$ and reduces oxygen carrying capacity of red blood cells(RBC). Cyanosis develops and aerobic oxygenation is hampered. Though intravenous methylene blue is the specific antidote it is not available commonly. Here we are reporting two cases of acute nitrobenzene poisoning and the role of methylene blue to save life.
\end{abstract}

Methaemoglobinemia is a potentially fatal and rare condition. The most common cause of methaemoglobinemia is the ingestion or inhalation of oxidizing agents such as nitrates and nitrites. ${ }^{1}$ Nitrobenzene is a poisonous agent not commonly encountered in clinical practice, which belongs to the group of aniline dyes \& causes methaemoglobinemia. It is also known as nitrobenzol or oil of mirbane, is a pale yellow oily liquid with a characteristic odour like bitter almond. Two rare cases of nitrobenzene ingestion came to our emergency department, with ingestion of nitrobenzene dye on two different days. They were treated with ventilatory support and exchange transfusion, but we could save only one life.

\section{Case Report}

\section{Case no-1:}

A 20 year old girl was admitted to our hospital emergency department in the evening, with a history of ingestion of about $100 \mathrm{ml}$ of a dye used in printing 12 hours ago. On examination she was cyanosed, her GCS (Glasgow coma scale) was $3\left(\mathrm{E}_{1} \mathrm{~V}_{1} \mathrm{M}_{1}\right)$, respiration was shallow with a respiratory rate of about $30 / \mathrm{min}$. Patient was immediately intubated and ventilated with SIMV (synchronised intermittent mandatory ventilation) mode. Peripheral and central cyanosis was observed, pulse $102 / \mathrm{min} \&$ blood pressure $110 / 70 \mathrm{~mm} \mathrm{Hg}$. On pulse oximetry $\mathrm{SpO}_{2}$ was only
$40 \%$. Her blood gas analysis showed $\mathrm{pH}-7.198$, $\mathrm{PaO}_{2}-516.7 \mathrm{mmHg}, \mathrm{PaCO}_{2}-21.2 \mathrm{mmHg}, \mathrm{HCO}_{3}$ $16.4 \mathrm{meq} / \mathrm{l}$. Serum electrolytes were within normal limits.

Haemoglobin was $11.2 \mathrm{gm} / \mathrm{dl}$, WBC count was $11,000 /$ dl. Serum urea, creatinine, liver function test all were within normal limits. Blood drawn for investigations was chocolate brown in colour. A filter paper test had revealed this. Acute nitrobenzene poisoning was suspected because dyes used in printing industry contains high amount of nitrobenzene. ${ }^{3}$ The absorption spectra showed wavelength peak of $258 \mathrm{~nm}$ matching with the pure nitrobenzene. Immediate gastric lavage was carried out. $100 \% \mathrm{O}_{2}$ was given through the ventilator. Due to non availability of intravenous methylene blue, we could not give her the specific antidote. Symptomatic treatment and vitamin $\mathrm{C}$ was started. Exchange transfusion was done twice with two units of packed red cells. Inspite of treatment her condition deteriorated. $8 \mathrm{hrs}$ after admission to the ICU she developed a cardiac arrest, from which she could not be revived.

\section{Case no-2}

A 26yr old young man, a worker in the dye industry came to our emergency department with similar complaints like in the above mentioned patient. His GCS was $3\left(E_{1} V_{1} M_{1}\right)$ at the time of presentation. He was intubated and was ventilated on SIMV mode. 
On examination peripheral and central cyanosis was observed, pulse was $94 / \mathrm{min}$ and blood pressure 124/74 mm Hg. On pulse oximetry $\mathrm{SpO}_{2}$ was $80 \%$. The blood gas analysis showed $\mathrm{pH}$-7.36, $\mathrm{PaO}_{2^{-}} 248.7 \mathrm{mmHg}, \quad \mathrm{PaCO}_{2^{-}}$ $31.2 \mathrm{mmHg}$, HCO3- $24.4 \mathrm{meq} / \mathrm{l}$. Serum electrolytes were within normal limits. Haemoglobin was $13.2 \mathrm{gm} / \mathrm{dl}$, WBC count was $9,400 /$ dl. Blood urea, serum creatinine, liver function tests were within normal limits. Blood drawn for investigation was chocolate brown in colour. A filter paper test had confirmed nitrobenzene poisoning. Treatment was similar to the previous patient, in addition he was given Methylene blue through Ryle's tube and repeated after two hours (The recommended route is intravenous only for methylene blue but due to non-availability of IV preparation we had to give it via Ryle's tube). Patient's condition improved due to methylene blue and $\mathrm{SpO}_{2}$ increased gradually. Patient was extubated after two days and after receiving treatment in the ICU for one more day, the patient was discharged.

\section{Discussion}

Nitrobenzene is used as a solvent, for the manufacture of cellulose ethers and acetate, as a flavouring agent, and as a perfume for soap etc. Therefore it is commonly available to factory workers and can be used as a means for committing suicide. Concentration of nitrobenzene in dyes used in printing industry can be upto $80 \%^{2}$. Hence ingestion of these dyes can cause severe nitrobenzene toxicity. Pathology behind nitrobenzene poisoning is that it oxidises $\mathrm{Fe}^{2+}$ of haemoglobin to $\mathrm{Fe}^{3+}$. Haemoglobin molecule is composed of four polypeptide chains associated with four haem groups containing an iron molecule in the reduced state or ferrous form $\left(\mathrm{Fe}^{2+}\right)$. Haemoglobin can accept and transport $\mathrm{O}_{2}$ only when the iron atom is in its ferrous form. When haemoglobin becomes oxidized, it is converted to the ferric state $\left(\mathrm{Fe}^{3+}\right)$ or methaemoglobin resulting in a condition called methaemoglobinemia $(\mathrm{MeHb})$ in which there is inhibition of binding and delivery of oxygen by a red blood cell. ${ }^{3}$ Methaemoglobin is not capable of transporting $\mathrm{O}_{2}$ because it lacks the electron that is needed to form a bond with $\mathrm{O}_{2}$. Blood normally contains approximately $1 \% \mathrm{MeHb}$ levels. ${ }^{1}$ The low level of $\mathrm{MeHb}$ is maintained by two important mechanisms. One is the hexosemonophosphate shunt pathway within the erythrocyte by which oxidizing agents are reduced by glutathione prior to the formation of $\mathrm{MeHb}$. The second mechanism against $\mathrm{MeHb}$ formation uses two enzymes systems: diaphorase-I (nicotinamide adenine dinucleotide methemoglobin reductase) and diaphorase -II (nicotinamide adenine dinucleotide phosphate methaemoglobin reductase). These two enzyme systems require NADH (Nicotinamide adenine dinucleotide) and NADPH (nicotinamide adenine dinucleotide phosphate) respectively to reduce $\mathrm{MeHb}$ to its original ferrous state. Diaphorase II quantitatively contributes only a small percentage of the reducing capacity of RBC. ${ }^{1}$ Symptoms also depends on concentration of methaemoglobin in blood.

\begin{tabular}{|l|l|}
\hline $\begin{array}{l}\text { Methaemoglobin } \\
\text { concentration }\end{array}$ & Symptoms \\
\hline $10-30 \%$ & Only cyanosis \\
\hline $30-50 \%$ & $\begin{array}{l}\text { Dyspnoea, } \\
\text { tachycardia, } \\
\text { dizziness, fatigue }\end{array}$ \\
\hline$>50 \%$ & Lethargy and stupor \\
\hline$>70 \%$ & Death \\
\hline
\end{tabular}

Features of nitrobenzene toxicity

Central nervous system - Headache, convulsions, paraesthesia, numbness of limbs and weakness, vertigo, dizziness etc.

Gastrointestinal-Hepatosplenomegaly, jaundice and altered liver fiunctions

Haematological- Haemolytic anaemia, Heinz bodies

Cardiovascular - Tachy and brady arrhythmias

Respiratory- Tachypnoea, cyanosis, dyspnoea

Skin- contact dermatitis

\section{Diagnosis}

The condition is diagnosed by the history of exposure, central cyanosis with not much depressant effect on respiration. There is persistent cyanosis on oxygen therapy without improvement in observed $\mathrm{SaO}_{2}$. There is also a difference between observed (pulse oximetry) and calculated (ABG) oxygen saturation. ${ }^{4}$

\section{Treatment}

It revolves mainly around gastric lavage. Stopping further exposure to the body through the skin, respiratory tract etc. $\mathrm{O}_{2}$ therapy, and artificial ventilation if needed. Methylene blue is the antidote of choice for acquired (toxic) 
methaemoglobinemia. ${ }^{5}$ It acts as an exogenous co-factor which greatly accelerates the NADPH dependent methaemoglobin reductase system. ${ }^{5}$ Methylene blue is indicated for acquired methaemoglobinemia when the level is greater than 35 to $40 \%$ and the patient has cardiorespiratory symptoms. ${ }^{5,6}$ The initial dose is 1 to $2 \mathrm{mg} / \mathrm{kg}$ or 0.1 to $0.2 \mathrm{ml} / \mathrm{kg}$ of the $3 \%$ solution given intravenously over five minutes. ${ }^{7}$ Response should occur within 1hour, repeated levels of methaemoglobin can be done to asses the progress. Though in higher doses it behaves as an oxidising agent and can cause asymptomatic methaemoglobinemia ${ }^{8}$ ascorbic acid is often mentioned as an alternative therapy, but its reducing effect is probably too slow to have significant benefit. ${ }^{8}$ Exchange transfusions equal to or less than the total volume and up to greater than twice the volume have been used. ${ }^{7}$ Dextrose should be given ${ }^{9}$ because the major source of NADH in the red blood cells is the catabolism of sugar through glycolysis. Dextrose is also necessary to form NADPH through the hexose monophosphate shunt, which is necessary for methylene blue to be effective. In patients with G6PD (Glucose-6-phosphate dehydrogenase) deficiency methylene blue therapy may be ineffective because they may not be able to produce sufficient NADPH to reduce methaemoglobin to leukomethylene blue. ${ }^{10}$

\section{Conclusion}

Nitrobenzene poisoning is a fatal condition but it can be treated if IV methylene blue is available on time, exposure to the compound is limited, and life support is available to the patient. Many cases have been reported previously., ${ }^{1,4,11,12}$ Most of these cases are managed with I.V methylene blue and therapy started very early. Most of the patients survived.

\section{References}

1. Patel. A. B., Dewan A, Upadhyay K. J, Patel S. A, Patel J. K. Chemically induced methemoglobinemia from acute nitrobenzene poisoning. The internet Journal of Laboratory Medicine. 2009 Volume 3 Number 2

2. Sodium 3-nitrobenzene sulfonate; www.made-in-china.com/.../Sodium-3Nitrobenzene-Sulfonate.html.

3. Wright RO, Lewander WJ, Woolf AD. Methemoglobinemia:aetiology, pharmacology and clinical management. Annals of Emergency Medicine. 1999; 34: 646-56.

4. Kumar A, Chawla R, Ahuja S, Nitrobenzene poisoning and spurious pulse oximetry. Anaesthesia 1990;45(11):949-51.

5. Curry S. Methaemoglobinemia. Ann Emerg Med 1982; 11:214-221.

6. Mansouri A. Review: Methaemoglobinemia. Am J Med Sci 1985; 29:200-209.

7. Schimelman MA, Soler JM, Muller HA. Methaemoglobinem: Nitrobenzene ingestion. J Am Coll Emerg Phys 1978; 7:406-408.

8. Whitwan JG, Taylor AR, White JM. Potential hazard of methylene blue. Anaesthesia 1979; 34:181-182.

9. Roigas H, Zoellner E, Jacobasch G, Schultze M, Rapoport S. Regulatory factors in methylene blue catalysis in erythrocytes. Eur J Biochem 1970; 12: 24-30

10. Harvey JW, Keitt AS. Studies of the efficacy and potential hazards of methylene blue therapy in aniline-induced methaemoglobinaemia. $\mathrm{Br} \mathrm{J}$ Haematol 1983;54: 29-41.

11. Mishra A; Narula AS; Anand AC. Methemoglobinemia in aniline dye poisoning. Medical Journal Armed Forces India. 1991; 47(3): 183-5.

12. Frank G. Sanders, M.D. Nitrobenzene poisoning with cyanosis._J Am Med Assoc. 1920;74(22):1518-1519. 